Southwood Report was cited as if it demonstrated as a matter of scientific certainty, rather than provisional opinion," the report notes. As a result, precautionary measures designed to protect both people and cattle from infection were not rigorously enforced.

Phillips also identifies specific breakdowns in communication that exacerbated the situation. For instance, many SEAC members remained unaware that mechanical recovery techniques, used to strip meat from the spinal column, were likely to allow traces of spinal cord to get into meat products. As a result, SEAC did not suggest that the practice should be banned until November 1995. And one key piece of evidence that first emerged in November 1990, showing that BSE had been passed to a breed of sheep resistant to scrapie, was never commented on by SEAC.

\section{Protecting the future}

Several principles to stop such failings are outlined by the Phillips report. It says that scientific advice should state the reasons for its conclusions, and that underlying assumptions should be made clear. Where appropriate, the advice should set out the different policy options and the implications of each.

The report also advocates greater openness, and stresses that officials and minister must recognize when the expertise of scientists ends, and decisions have moved into the

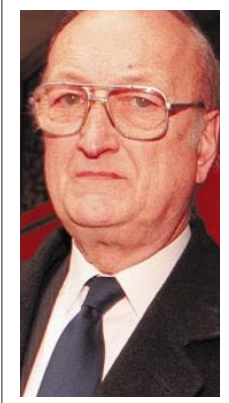
policy arena. "Scientist were expected to provide all the answers, where sometimes this was not their proper role," says Phillips.

The recommendations will not surprise British scientists, as almost all of them have already been introduced by Robert May, the government's chief sciSouthwood: his panel comes under fire. entific adviser until two

What will surprise some scientists are the statements about BSE's origins made in the Phillips report. It says that the disease "probably originated from a novel source in the early 1970s, possibly a cow or other animal that developed disease as a consequence of gene mutation". Some feel that this goes beyond the available evidence. "It is likely to be impossible to know," says Anderson, who will soon take up a post at Imperial College, London.

The current government seems to feel this point needs clarification, and has said it intends to commission an independent review of scientific understanding of the origins of the BSE epidemic. Researchers in the field hope that this does not deflect attention from the most urgent priorities, which include developing a test to identify animals and people incubating the disease, and drugs to treat vCJD victims.

http://wwww.bseinquiry.gov.uk

\title{
Scientific turf war 'delayed potentially vital research'
}

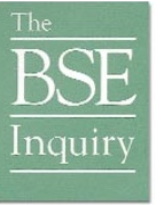

David Dickson, London

Individual scientists may have largely escaped criticism in Britain's BSE inquiry, chaired by Lord Phillips. But the inquiry's report sharply highlights critical weaknesses in the way research decisions were made.

In particular, the report suggests that turf fights between the research councils and government departments may have delayed vital research in the early 1990s. Such tensions, it reveals, undermined efforts in 1990 by Donald Acheson, then chief medical officer at the Department of Health, to give responsibility for BSE-related research to a single research supremo. Scientists looking at the implications of the BSE crisis are likely to focus on the factors that led to this failure.

Acheson wanted a single individual to be responsible for identifying key research needs and commissioning the appropriate additional research in a way that had already been successfully applied to the AIDS epidemic. The Phillips report identifies various areas - such as experimental testing of the 'scrapie' hypothesis (see main story) and the development of a reliable diagnostic blood test - where progress might have been more rapid if a supremo had been in place.

But, as evidence submitted to the inquiry shows, the proposal fell victim to a basic distrust between government officials and scientists working in universities or for the research councils. In particular, officials from the Ministry of Agriculture, Fisheries and Food (MAFF) remained adamant that any attempt to develop and monitor a broad research agenda should be under their control - and be directed by a veterinary expert rather than a scientist with a background in fundamental research.

At the same time, according to evidence presented to the inquiry, representatives of the two research councils directly involved - the Medical Research Council and the Agricultural and Food Research Council were keen to remain independent from anything that felt like government interference.

These differences could not be reconciled. And the minutes of a subsequent meeting of government officials records a general feeling that the supremo idea "should be left on one side to die a natural death".

Apart from one area of research - the possibility of maternal transmission of BSE from cows to their calves - the Phillips report rejects the charge that BSE research suffered from inadequate funding.

But it does draw attention to the lack of collaboration between scientists working in government laboratories and non-government researchers. For example, the report points out that scientists from MAFF's Central Veterinary Laboratory (CVL) in Weybridge, Surrey, held back initially from consulting scientists at the Neuropathogenesis Unit (NPU) in Edinburgh. "If the CVL had consulted them at this stage, the NPU would have confirmed that there were very strong indications that this was indeed a new Transmissible Spongiform Encephalopathy," it says.

The evidence unearthed by the Phillips inquiry has provided a rich source of ammunition for those keen to see a reassessment of the division of responsibilities between government and non-government scientists on topics of public concern.

Peter Cotgreave, for example, director of the lobby group Save British Science, says that the one clear lesson is "recognition of the need for the scientific community to get more closely involved" in deciding on research priorities in areas with important policy implications.

Eric Millstone, of the Science Policy Research Unit at the University of Sussex, agrees - but says that this does not necessarily mean passing responsibility for choosing priorities to bodies such as the research councils. "Phillips talks as if scientific research could and should be conducted in a policy vacuum," says Millstone. "But that is unrealistic. The failure of BSE was not that BSE research was being overseen by a government department, but that it was the wrong department."

The Royal Society has already announced plans to carry out a rapid review of the lessons of the BSE crisis for the interaction between the government and science advisory committees. Reacting with unprecedented speed, it has promised that its conclusions will be completed in December.

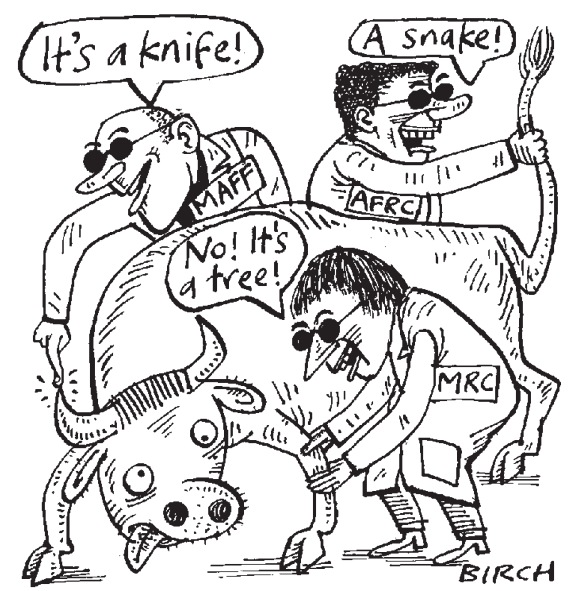

